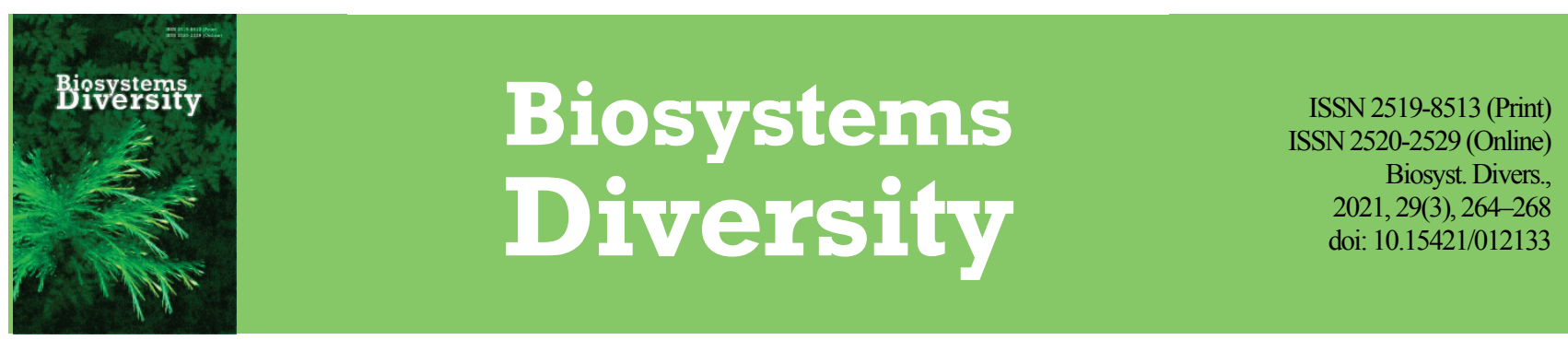

\title{
Allelopathic potential and cytostatic activity of Antarctic moss Sanionia georgicouncinata (Amblystegiaceae)
}

\author{
O. Dziuba*, A. Liubinska*, P. Khoyetskyy**, T. Bedernichek* \\ *M. M. Gryshko National Botanical Garden of NAS of Ukraine, Kyiv, Ukraine \\ **Ukrainian National Forestry University, Lviv, Ukraine
}

Article info

Received 05.07.2021

Received in revised form 01.08 .2021

Accepted 02.08.2021

M. M. Gryshko National

Botanical Garden

of NAS of Ukraine,

Tymiriazevska st., 1 ,

Kyiv, 01014, Ukraine

Tel.: +38-063-353-02-86

E-mail:

bedernichek@gmail.com

Ukrainian National

Forestry University,

Kobylianska st., 1,

Lviv, 79005, Ukraine.

Tel.: +38-050-229-51-35.

E-mail:

khovetskyy@gmail.com

Dziuba, O., Liubinska, A., Khoyetskyy, P., \& Bedernichek, T. (2021). Allelopathic potential and cytostatic activity of Antarctic moss Sanionia georgicouncinata (Amblystegiaceae). Biosystems Diversity, 29(3), 264-268. doi:10.15421/012133

From the first half of the XX century, the maritime Antarctic was a region with high regional warming rates. At the beginning of the XXI century, regional warming strongly slowed down, but during the next twenty years the near-surface temperatures and mean annual precipitation at the Antarctic Peninsula will most probably increase. Higher temperatures and precipitation make the conditions in the maritime Antarctic more favourable for plants, including invasive species. Moreover, the increasing number of Antarctic tourists unintentionally transport thousands of seeds to the Antarctic on their clothes and equipment. In such circumstances, it is important to evaluate possible defensive mechanisms of native plant species, including their allelopathic potential. The objective of this study was to evaluate the allelopathic potential and cytostatic activity of Sanionia georgicouncinata. This species is widespread in the maritime Antarctic and is one of the most abundant moss species on the Argentine Islands (Wilhelm Archipelago). Seeds of cucumber Cucumis sativus, radish Raphanus raphanistrum subsp. sativus, wheat Triticum vulgare, and amaranth Amaranthus paniculatus were used as bioassay species. Fresh green biomass of $S$. georgicouncinata was used to prepare aqueous extracts with $1: 10,1: 50$, and $1: 100$ plant to water ratios. The average root length of wheat sprouts and cucumber sprouts in distilled water did not differ significantly from those in plant extracts. The root length of radish sprouts in $1: 50$ plant extract was significantly shorter than in distilled water. Meanwhile, in $1: 50$ and $1: 100$ water extracts, roots of amaranth plants were significantly longer than in water. The number of lateral roots of cucumber sprouts in water and studied aqueous extracts varied from 1 to 6 with medians from 3 to 4 . The medians of control (distilled water) and sample groups (aqueous extracts) did not differ significantly, but only $38.1 \pm 6.1 \%$ of cucumber sprouts developed lateral roots in the $1: 10$ aqueous extract of $S$. georgicouncinata, and even less $-28.3 \pm 7.5 \%$ in the $1: 50$ aqueous extract. The results of this study show that the allelopathic potential of $S$. georgicouncinata is low. However, a significant cytostatic activity of the studied extracts shows that this species may still affect other plants and animals. Further research is needed to evaluate the impact of the studied extracts on root growth and germination of the invasive plants, particularly Poa аппиа.

Keywords: bioassay; allelopathy; maritime Antarctic; Argentine Islands; test plant; root growth.

\section{Introduction}

At the end of the XX century, the Antarctic Peninsula and the surrounding islands were the regions with the highest rates of mean temperature increase on the planet (Vaughan et al., 2003). Although, at the beginning of the XXI century warming on the Antarctic Peninsula was not observed (Turner et al., 2016), in 2020 several temperature records were broken in the Antarctic (Robinson et al., 2020). A new record maximum temperature of $18.4{ }^{\circ} \mathrm{C}$ was reached on 6th February 2020 (Esperanza Base, Antarctic Peninsula) and three days later $20.75{ }^{\circ} \mathrm{C}$ was reported (Marambio Base, Seymour Island). Bozkurt et al. (2021) concluded that over the next two decades mean annual near-surface temperatures and mean annual precipitation on the Antarctic Peninsula will most probably increase. Higher temperatures and precipitation will make the maritime Antarctic more favourable for a wide range of species, including plant species, that could not withstand low temperatures before (Gutt et al., 2021).

Chown et al. (2012) showed that the Antarctic tourists and researchers carry on average 9.5 seeds per person on their clothes, bags, shoes, etc. Similar trends were reported by Ware et al. (2012) for the High Arctic (Svalbard Archipelago). Therefore, the risk of plant invasions in polar and particularly Antarctic ecosystems under such circumstances increases.

Moreover, for sub-Antarctic Marion Island Haussmann et al. (2013) showed that fur seals facilitate the establishment of exotic vascular plants. They have found that seal-affected sites were inhabited by many alien plant species, including such invaders as Poa annua L. and Sagina procumbens L. Impact of pinnipeds on the terrestrial ecosystems and in par- ticular soils in the Antarctic is not well known yet (Bedernichek et al., 2020). However, taking into account a rapid increase of the fur seal population and observation from Marion Island, they are expected to transport seeds of alien plants to the maritime Antarctic as well.

Currently, only several non-native plants have established populations in the Antarctic. A recent study by Molina-Montenegro et al. (2019) showed the interaction between one of the most widespread invasive plants in the Antarctic Poa annua L., Deschampsia antarctica Desv., and Colobanthus quitensis (Kunth) Bartl. in field garden experiments. Moreover, the significant role of interactions between native plant species in the Antarctic was observed before. Casanova-Katny \& Cavieres (2012) reported that Antarctic moss carpets facilitate growth but not survival of Deschampsia antarctica. Also, a preliminary study by Zaimenko et al. (2016) shows that the allelopathic activity of the Antarctic plants may be temperature-related. They studied the allelopathic activity of the aboveground biomass of $D$. antarctica and have found that aqueous extraction at $10{ }^{\circ} \mathrm{C}$ was effective and the root length of Lepidium sativum $\mathrm{L}$. and Cucumis sativus L. significantly decreased compared to those in extracts prepared at $5{ }^{\circ} \mathrm{C}$. In this context, it is important to evaluate the protective mechanisms of native plant species and, first of all, their allelopathic activity to understand how effectively they may react to non-native plant species. This includes, but is not limited to the evaluation of phytotoxic and cytostatic properties of plant extracts and eluates. Unlike the higher plants, there is surprisingly little data about the allelopathy of bryophytes (Kato-Noguchi et al., 2010) and especially about the allelopathic activity of mosses in the Antarctic. 
The objective of this study was to evaluate the allelopathic potential and cytostatic activity of Sanionia georgicouncinata (Müll. Hal.) Ochyra. This species is widespread in the maritime Antarctic and is one of the most abundant moss species on the Argentine Islands (Wilhelm Archipelago). Parnikoza et al. (2016) define the moss carpet communities which include Brachytecium astrosalebrosum (Müll. Hal.) Kindb., Sanionia uncinata (Hedv.) Loeske, and S. georgicouncinata as typical for the Argentine Islands. There is information about the possible allelopathic activity of this species regarding its positive impact on the growth of $D$. antarctica (Casanova-Katny \& Cavieres, 2012). Also, Ivanova et al. (2007) isolated two cinnamoyl bibenzyls from $S$. georgicouncinata, identified as sanionin A and sanionin B with antibacterial activity and weak cytotoxicity. Therefore, we expected this species to have moderate to high allelopathic activity, which may be a defensive mechanism against alien plant species, including possible invaders.

\section{Materials and methods}

Soil samples with native plant species were taken in 2016 in the vicinity of Akademik Vernadsky Station (Fig. 1) on Galindez Island and Skua Island (Argentine Islands, Wilhelm Archipelago). Sampling locations had different vegetation, but at many of them $S$. georgicouncinata was either one of the dominant species or a part of moss carpets that consisted of several moss species and sometimes included $D$. antarctica (Fig. 2a). For this study, the samples of plants with soil were placed in plastic containers, sealed, and transported to the laboratory in Ukraine. During transportation, the sealed containers were opened once every two days and sprayed with distilled water if necessary. All the samples were stabilized at $5{ }^{\circ} \mathrm{C}$ for three days and then used for further research.

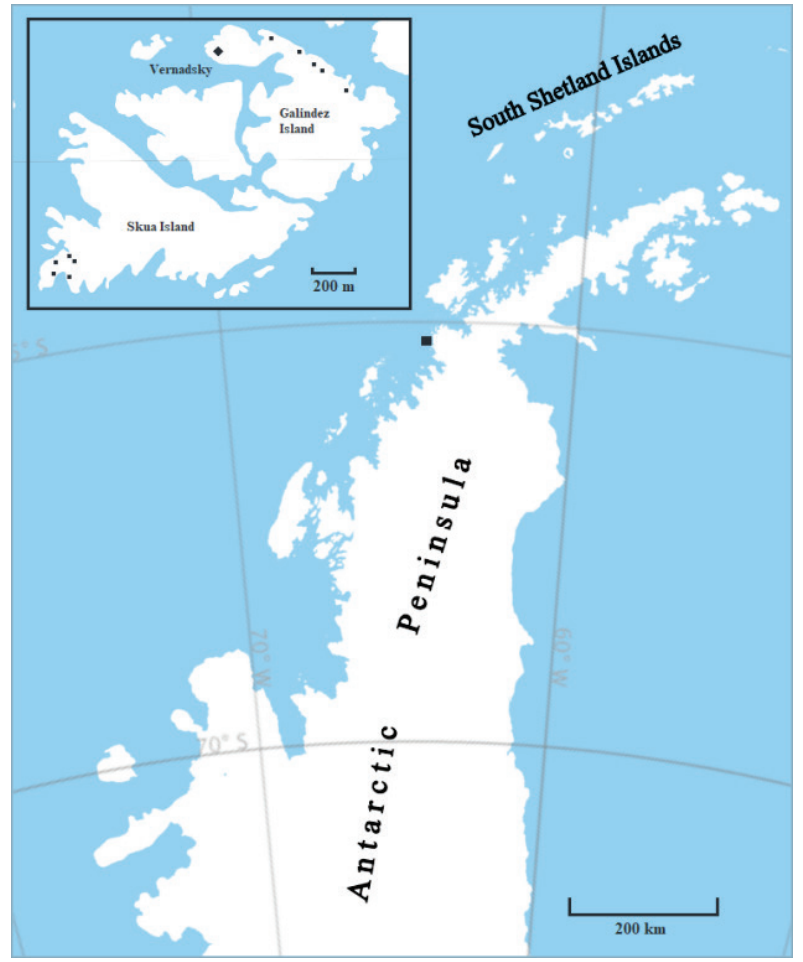

Fig. 1. Map of the Antarctic Peninsula with the Argentine Islands (inset) indicating sampling locations

After the plants had arrived, we sampled fresh green biomass to evaluate the content of pigments before putting the plants into the growing chamber. The spectral determination of chlorophylls a and $b$, and total carotenoids in DMSO was performed according to the recommendations of Wellburn (1994). Content of pigments may affect the allelopathic activity of the plant extracts. Therefore, it should be as close as possible to in situ conditions. Unfortunately, it was impossible to evaluate the content of the pigments in the Antarctic at the station immediately after sampling. Therefore, we had no other option but to determine chlorophylls and carotenoids right after the plants had arrived and then once again after
10 days. Such a period was chosen because it took approximately 10 days from sampling the plants with soil in the Antarctic till the samples arrived in the laboratory.

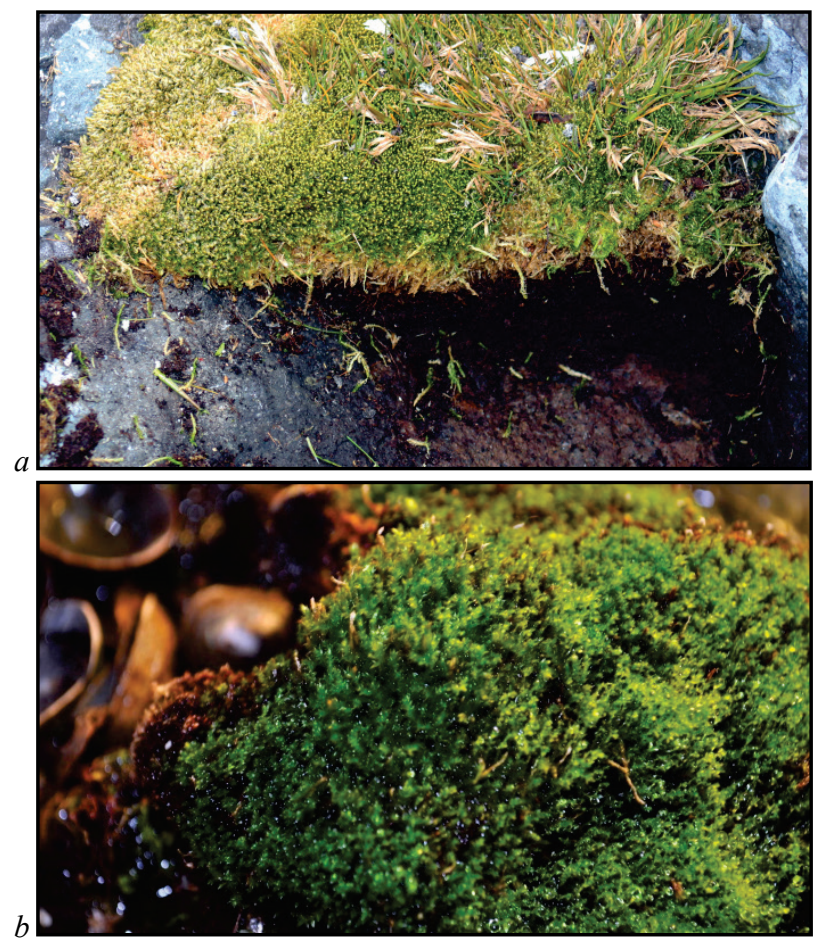

Fig. 2. Sampling plot on Skua Island:

moss carpet with Sanionia georgicouncinata and Deschampsia antarctica (a), and S. georgicouncinata in the growing chamber before sampling green biomass $(b)$

Allelopathic activity of plant extracts was studied following the recommendations of Grodzinsky (1987). Briefly, for each test $500 \mathrm{mg}$ of fresh green biomass of S. georgicouncinata (Fig. 2) were rinsed in distilled water for one minute and placed into a $100 \mathrm{~mL}$ conical flask. 5, 25, and 50 $\mathrm{mL}$ of distilled water were added to the flasks to obtain extracts with 1:10, 1:50, and 1:100 plant biomass to water ratios. The flasks were shaken 30 minutes on the orbital shaker and then placed into a thermostat at $4{ }^{\circ} \mathrm{C}$ for 12 hours. The electrical conductivity and $\mathrm{pH}$ of the extracts were determined with S47 SevenMulti (Mettler Toledo, USA). Seeds of cucumber Cucumis sativus, radish Raphanus raphanistrum subsp. sativus (L.) Domin, wheat Triticum vulgare L., and amaranth Amaranthus paniculatus L. were used as bioassay species. Previously we noticed that rates of germination and root elongation for cucumber sprouts strongly depend on the cultivar and age of the seed. In this study seeds of the Konkurent cultivar were used. Seeds of all bioassay species were soaked overnight in distilled water and then placed on filter paper soaked in distilled water. In approximately 12 hours, when the first roots appeared, seeds with roots of similar length were used in the following stages of the study. For each bioassay, five separate Petri dishes were used. 10 seeds of each bioassay species were placed in a Petri dish on a dry filter paper. $5 \mathrm{~mL}$ of distilled water, 1 : $10,1: 50$, and $1: 100$ plant extracts were added to separate Petri dishes. Petri dishes were covered to reduce evaporation and placed into the thermostat at $27{ }^{\circ} \mathrm{C}$. After 24 hours, we removed the sprouts, covered the roots with a cover glass, and took photos of the sprouts. Sprout length was measured in ImageJ2 (Rueden et al., 2017). The cytostatic activity of the studied extracts was determined following the recommendation of Ivanov (2011). Briefly, two-day-old cucumber sprouts were placed in Petri dishes on filter paper, that was moistened either with distilled water (control) or plant extracts. The next day, the number of lateral roots was counted. The cytostatics are known to stop the emergence of lateral roots by slowing down cell division in the meristem. Therefore, the fewer lateral roots the sprouts had - the stronger cytostatic activity was observed. Dino-Lite Pro digital microscope (Dino-Lite, Taiwan) was used to take photographs of the roots. 
Minitab 19 (Minitab LLC, USA) was used to build the boxplots and to evaluate the difference between the medians of the control samples (water) and test samples (1:10,1:50, and $1: 100$ extracts). The MannWhitney test was used to determine whether the difference in medians of control and study groups is statistically significant $(\mathrm{P}<0.05)$. Data is presented as an arithmetic mean with standard deviation $(\mathrm{x} \pm \mathrm{SD})$.

\section{Results}

Content of chlorophyll a, chlorophyll $\mathrm{b}$, and total carotenoids in fresh green biomass of $S$. georgicouncinata was determined in the plants immediately after they arrived in the lab and then ten days later, after the incubation in the growing chamber at $5{ }^{\circ} \mathrm{C}$ (Table 1). No significant differences in the content of chlorophylls and carotenoids were found before and after incubation.

\section{Table 1}

Content of chlorophyll a, chlorophyll b, total chlorophyll (chlorophyll a + chlorophyll b), and total carotenoids in fresh green biomass of Sanionia georgicouncinata before and after ten-day incubation $(\mathrm{x} \pm \mathrm{SD}, \mathrm{n}=5, \mathrm{mg} / \mathrm{g}$ dry weight $)$

\begin{tabular}{lcccc}
\hline \multicolumn{1}{c}{ Treatments } & $\begin{array}{c}\text { Chlorophyll } a, \text { Chlorophyll } b, \\
\text { mg/g dry } \\
\text { weight }\end{array}$ & $\begin{array}{c}\text { Total chloro- } \\
\text { weight } \\
\text { whyll, } \mathrm{mg} / \mathrm{g}\end{array}$ & $\begin{array}{c}\text { Total carote- } \\
\text { dry weight }\end{array}$ & $\begin{array}{c}\text { noids, } \mathrm{mg} / \mathrm{g} \\
\text { dry weight }\end{array}$ \\
\hline Before incubation & $1.30 \pm 0.38$ & $2.37 \pm 0.68$ & $3.67 \pm 0.93$ & $0.62 \pm 0.17$ \\
After incubation & $1.13 \pm 0.24$ & $2.54 \pm 0.42$ & $3.21 \pm 0.54$ & $0.51 \pm 0.11$ \\
\hline
\end{tabular}

Note: no significant differences were found according to the Mann-Whitney statistics.

The first extracts were prepared with fresh samples of plant biomass that were not rinsed in the distilled water. The electrical conductivity of the distilled water was $5.03 \pm 0.14 \mu \mathrm{S} / \mathrm{cm}(\mathrm{n}=5)$. The electrical conductivity of the plant extracts was $71.85,118.25$, and $480.5 \mu \mathrm{S} / \mathrm{cm}$ for $1: 100,1$ : 50 , and $1: 10$ extracts respectively $(n=1)$. During the transportation from the Antarctic, the plants were watered with distilled water, dispersed from a water sprayer. We considered it enough to wash the possible residues

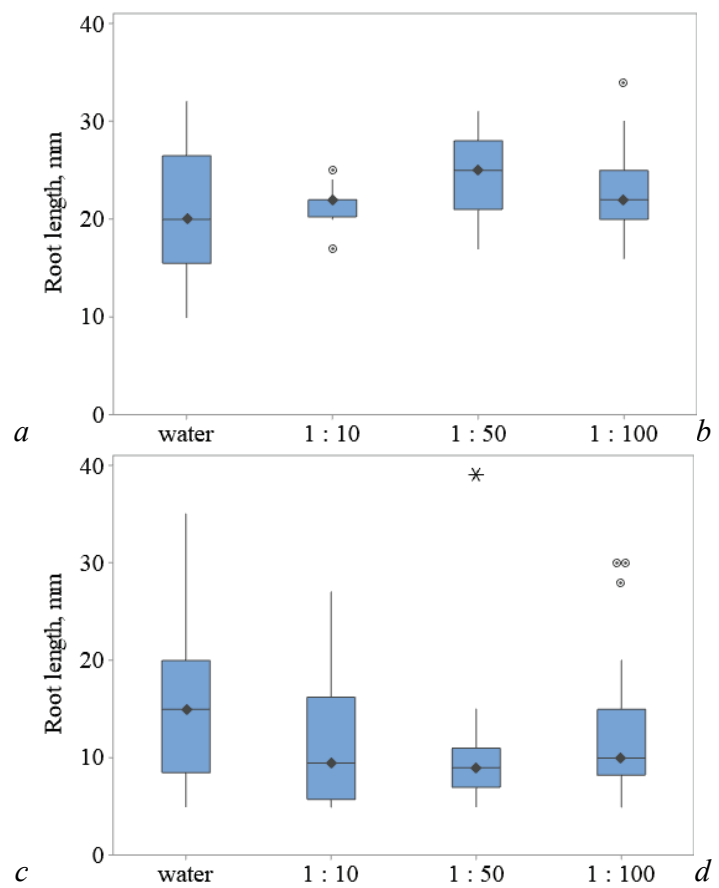

that could accumulate on the plants with aerosols from the seawater. Unfortunately, high values of electrical conductivity of the obtained extracts showed that most probably some of the salts were left on the plants and biased the results. For all the further experiments, the plants were rinsed in distilled water for one minute. Electrical conductivity of the newly prepared extracts (Table 2) was much lower: $23.50,42.05$, and $172.8 \mu \mathrm{S} / \mathrm{cm}$ in $1: 100,1: 50$, and $1: 10$ extracts respectively $(\mathrm{n}=5)$. The $\mathrm{pH}$ of the distilled water was 5.92 . The acidity of the plant extracts was considerably higher: $\mathrm{pH}$ values varied from 4.08 to 4.21 in the most diluted $1: 100$ extract and from 3.75 to 3.91 in the most concentrated one $(1: 10)$. Interestingly, while the electrical conductivity of the extracts strongly decreased with dilution, the $\mathrm{pH}$ values of all the extracts were comparable and varied in a quite narrow range from 3.75 to 4.21 .

\section{Table 2}

Electrical conductivity (EC), and $\mathrm{pH}$ of distilled water and aqueous extracts of Sanionia georgicouncinata $(\mathrm{x} \pm \mathrm{SD}, \mathrm{n}=5)$

\begin{tabular}{lcccc}
\hline \multirow{2}{*}{ Treatments } & \multirow{2}{*}{$\mathrm{EC}, \mu \mathrm{S} / \mathrm{cm}$} & \multicolumn{3}{c}{$\mathrm{pH}$} \\
\cline { 3 - 5 } & & median & maximum & minimum \\
\hline water & $5.03 \pm 0.14$ & 5.92 & 6.05 & 5.91 \\
$1: 100$ & $23.50 \pm 13.24$ & 4.11 & 4.21 & 4.08 \\
$1: 50$ & $42.05 \pm 11.07$ & 4.07 & 4.07 & 4.02 \\
$1: 10$ & $172.8 \pm 24.11$ & 3.89 & 3.91 & 3.75 \\
\hline
\end{tabular}

Note: electrical conductivity and $\mathrm{pH}$ of all the studied extracts differed significantly $(\mathrm{P}<0.01)$ from the control (distilled water) according to the Mann-Whitney statistics.

The results of our preliminary study show that the allelopathic activity of $S$. georgicouncinata is low (Fig. 3). The average root length of wheat sprouts in distilled water was $20.81 \pm 6.68 \mathrm{~mm}$. Root length in the studied $1: 10,1: 50$, and $1: 100$ extracts was $21.55 \pm 1.70,24.84 \pm 4.32$, and $22.75 \pm 4.68 \mathrm{~mm}$. Root length in none of the studied extracts differed significantly from those in distilled water. The lowest $p$-value $(\mathrm{W}=232$, $\mathrm{P}=0.066$ ) was found for the pair distilled water $-1: 50$ plant extract, although the observed difference still was not significant.

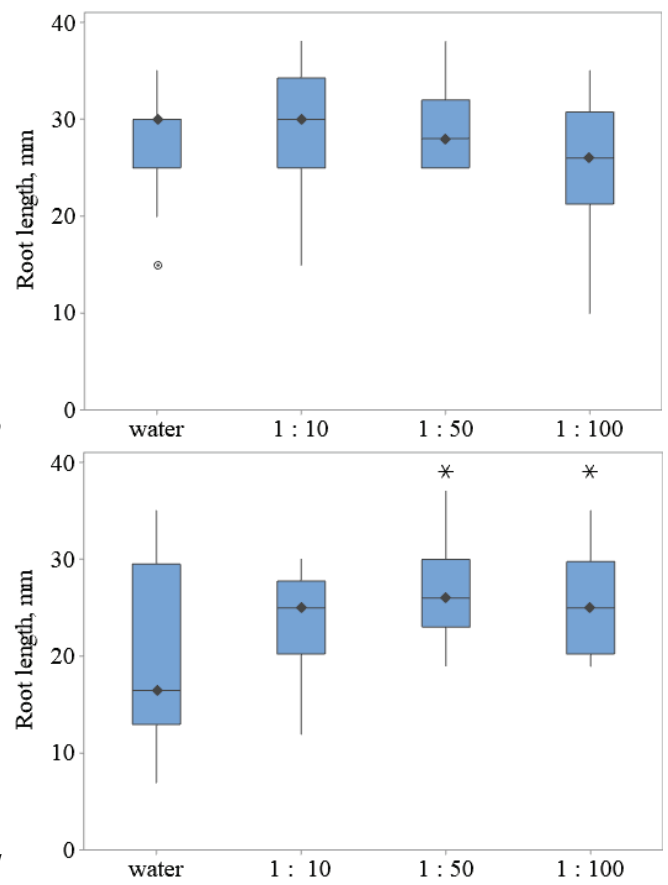

Fig. 3. Root length of wheat sprouts $(a)$, cucumber sprouts $(b)$, radish sprouts $(c)$, and amaranth sprouts $(d)$ in distilled water and aqueous extracts of Sanionia georgicouncinata: the median is represented by the line with a rhombus in the interquartile range box; the whiskers show the ranges for the bottom $25 \%$ and the top $25 \%$ of the data values, excluding the outliers; asterisks identify the extracts, where root length significantly $(\mathrm{P}<0.05)$ differed from the control (distilled water) according to the Mann-Whitney statistics ( $n=20)$

The length of the main roots of cucumber sprouts in distilled water was $27.5 \pm 4.73 \mathrm{~mm}$. In $1: 10,1: 50$, and $1: 100$ aqueous plant extracts it was $28.95 \pm 5.80,29.16 \pm 4.17$, and $26.65 \pm 6.53 \mathrm{~mm}$. Root length in distilled water did not differ significantly $(\mathrm{P}>0.05)$ from those in plant extracts and the P-value varied from 0.37 to 0.81 .
We have found that the root length of radish sprouts in distilled water and $1: 10$, as well as $1: 100$ plant extracts, differed insignificantly. However, root length in $1: 50$ plant extract was significantly $(\mathrm{P}=0.036, \mathrm{~W}=$ 388) shorter than in the distilled water (Fig. 3c). The last species that we used in this study was amaranth. Root length of amaranth sprouts in dis- 
tilled water and $1: 10$ plant extract differed insignificantly $(\mathrm{P}=0.102, \mathrm{~W}=$ 349). However, in $1: 50(\mathrm{P}=0.012, \mathrm{~W}=316.5)$ and $1: 100(\mathrm{P}=0.019$, $\mathrm{W}=322.5)$ water extracts, roots of amaranth plants were significantly longer than in the distilled water (Fig. 3d).

Although the phytotoxicity of the studied extracts was relatively low, noticeable cytostatic activity was found in $1: 10$ and $1: 50$ extracts (Fig. 4). Only $38.1 \pm 6.1 \%$ of cucumber sprouts developed lateral roots in the $1: 10$ aqueous extract of $S$. georgicouncinata, and even less $-28.3 \pm$ $7.5 \%$ in the $1: 50$ aqueous extract.

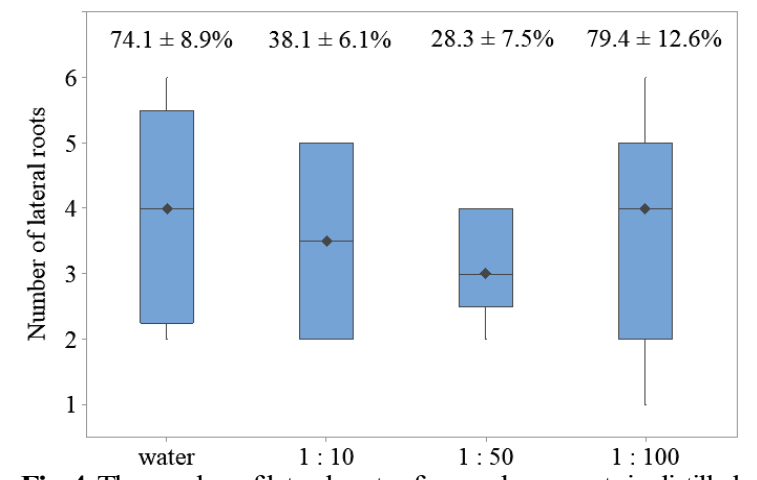

Fig. 4. The number of lateral roots of cucumber sprouts in distilled water and aqueous extracts of Sanionia georgicouncinata after 24-hour incubation: the median is represented by the line with a rhombus in the interquartile range box; the whiskers show the ranges for the bottom $25 \%$ and the top $25 \%$ of the data values; percentages show how many sprouts

developed lateral roots out of 50 seeds in five Petri dishes $(x \pm S D)$

The number of lateral roots in water and studied aqueous extracts varied from 1 to 6 with medians from 3 to 4 . The medians of control (distilled water) and sample groups (aqueous extracts) did not differ significantly $(\mathrm{P}>0.05)$ according to the Mann-Whitney statistics. Moreover, the emergence of lateral roots did not approach the root tip as it should be if root elongation was slowed down. The shorter lateral roots numbered 3,4 , and 5 appeared about ten hours after the longer roots numbered 1 and 2 (Fig. 5). The distance between these older and newly emerged roots was short, just several millimeters. We observed such a trend for distilled water and all the studied plant extracts.

\section{Discussion}

The content of pigments in the studied plants of $S$. georgicouncinata before and after ten-day incubation did not change significantly. Although we tried to create the temperature and light conditions as close as possible to those in situ, there definitely was a difference. The fact that the content of chlorophylls and carotenoids did not change significantly during 10 days in the growing box means that these values change slowly. With certain limitations, we may consider that content of these pigments was approximately the same in situ. Although using DMSO for extraction of chlorophylls and carotenoids is not the best method and sometimes the obtained results are not comparable with other extractants due to possible coextraction of other substances like tannins and other phenolics, it still extracts reproducible amounts of pigments (Minocha et al., 2009). Therefore, the method itself is quite suitable for the current study, where the same plants were compared in different periods.

Rinsing the plants in distilled water is an important step for extracts' preparation. Our first unsuccessful attempt led to biased results - the obtained extracts were heavily contaminated with soluble salts, most probably $\mathrm{NaCl}$. Such high concentrations as were observed in the experiment may bias the results and affect the phytotoxic activity determined with bioassays. For example, Fry (2017) reported that amaranth hypocotyl elongation was promoted not by lepidimoide, but by potassium. The plant extracts, obtained after rinsing the mosses in distilled water contained a much lower amount of soluble salts, and the electrical conductivity of the most concentrated extract $172.8 \pm 24.1 \mu \mathrm{S} / \mathrm{cm}$ was not enough to inhibit root elongation of the test plants due to the salt stress. The $\mathrm{pH}$ values of the extracts were close to 4 and did not differ significantly enough to explain the differences in root growth of the test plants by the acidity level.

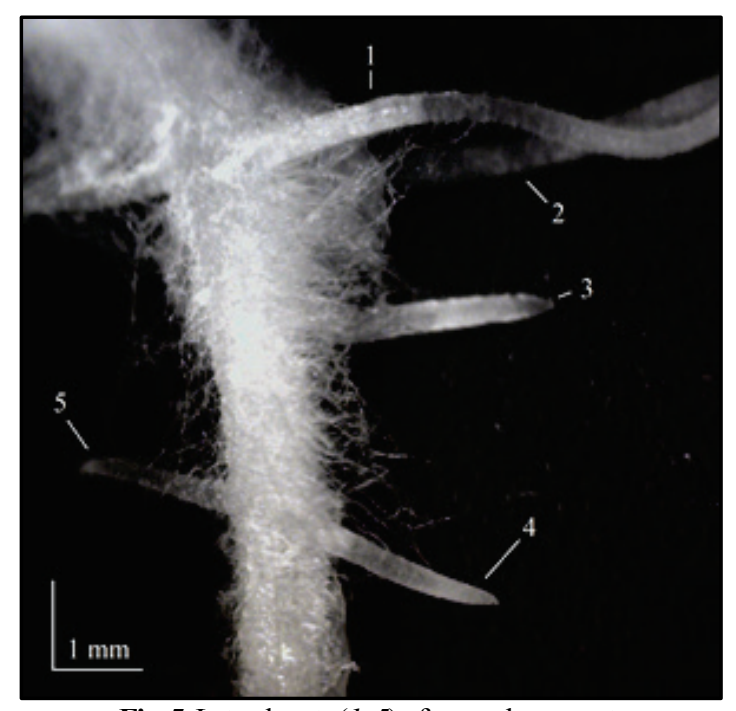

Fig. 5. Lateral roots (1-5) of cucumber sprouts in distilled after 24-hour incubation

Wheat sprouts usually are relatively tolerant to allelochemicals (Grodzinsky, 1987; Moroz, 1990) and were used in this study, because we expected the allelopathic activity of S. georgicouncinata to be much higher than it was observed. Cucumber sprouts usually are a more sensitive bioassay compared to wheat and are sometimes used after the wheat to evaluate the allelopathic activity of plants with low to moderate allelopathic potential (Munzuroglu \& Geckil, 2002). Also, cucumber is widely used in some seed germination and root elongation tests (Wang, 1991; Wang et al., 2001). The fact that we did not observe statistically significant differences for wheat and cucumber sprouts suggests that the allelopathic activity of the studied plant extracts is low. At least it was low enough not to inhibit the growth of the primary root. The third bioassay we used in this study was radish sprouts. According to Aliotta et al. (1993), radish germination and root growth are strongly inhibited by a number of allelochemicals, including coumarin and phenylpropanoids. If so, the strongest inhibition should be observed in $1: 10$ and $1: 50$ plant extracts, but it was found for $1: 50$ extract only. Although, it remains unclear why the $1: 50$ plant extracts were phytotoxic and the extract $1: 10$ was not, one of the reasonable explanations may be the low solubility of certain allelochemicals in aqueous extracts. Whitehead et al. (2018) suggested that water might not be an adequate extractant for allelochemicals from the mosses, because most of such substances are lipophilic. Due to very low solubility in water, it may happen that $1: 10$ aqueous plant extracts did not contain enough molecules of those substances that cause phytotoxic effect. However, future studies are needed to verify this hypothesis.

In our study, the amaranth sprouts reacted differently in comparison to the previously mentioned bioassays. Although amaranth plants are known for high allelopathic activity (Prinsloo \& Du Plooy, 2018), they are also used as a quite sensitive bioassay species to evaluate the allelopathic activity of other plants. For example, Sangeetha \& Baskar (2015) reported that Helianthus annuus L., Ageratum conyzoides L., and Fagopyrum esculentum Moench strongly inhibited the growth of amaranth plants. However, in our study, we observed the opposite - aqueous extracts of S. georgicouncinata stimulated root growth of amaranth sprouts. We tend to explain the observed reaction by the hormesis phenomenon. As it was previously showed by Hadacek et al. (2011), a high concentration of allelochemicals may be phytotoxic, while a low concentration of the same substances - stimulating.

Finally, the significant cytostatic activity of the aqueous extracts of S. georgicouncinata was observed in this study. Ivanov (2011, p. 1087) pointed out that "Cytostatics stop the emergence of lateral roots, whereas highly toxic substances strongly inhibit the growth of the primary root but do not stop the emergence of lateral roots". When phytotoxic and cytostatic activities are observed simultaneously, most of the lateral roots are located close to the root tip. In our study, the length of the main root was not affected by the plant extracts. Therefore, they showed insignificant phytotoxic activity, but noticeable cytostatic activity. In theory, significant 
cytostatic activity may affect the root development of other plants, including invasive species. Moreover, cytostatic substances may affect not only plants but animals as well. In this context, the microarthropod community of moss-turf habitats, which is well studied on the Argentine Islands (Caruso et al., 2013) may be a suitable object for future research.

Further research should study whether or not those extracts that had cytostatic activity affect root development of certain invasive plant species, particularly Poa. annua. Kovár et al. (2013) reported that certain turfgrass species affect germination, initial growth, and root development of $P$. аппиа. There is no information about the impact of bryophytes on this invasive species. This data is important, especially for the Antarctic, to develop adequate management plans for the territories affected or potentially affected by invasive plant species. Although none of the invasive plant species has been found on Argentine Islands yet, there is a decent possibility of such invasions in the nearest future. Fowbert \& Lewis Smith (1994) reported rapid population increases in native vascular plants in the Argentine Islands between 1964 and 1990, which means that conditions for higher plants there became more favourable.

\section{Conclusions}

During this research, we used four bioassays and three different concentrations of plant extracts for each of them. Among these twelve groups, only one $-1: 50$ extract of fresh biomass of Sanionia georgicouncinata inhibited root growth of radish and two extracts $(1: 50$ and $1: 100)$ stimulated the root growth of amaranth sprouts. These results show that the allelopathic potential of S. georgicouncinata is low. However, a significant cytostatic activity of the studied extracts may still affect other plant and animal species, including invasive. Further research is needed to evaluate the impact of the studied aqueous extracts on root growth and germination of the invasive plants, particularly P. аппиa.

This study was supported by the State Institution "National Antarctic Scientific Center", the project No. 0117U003733. We also are grateful to Dr. Tetyana Partyka and Alona Krotiuk for their helpful comments on the previous version of this article.

\section{References}

Aliotta, G., Cafiero, G., Fiorentino, A., \& Strumia, S. (1993). Inhibition of radish germination and root growth by coumarin and phenylpropanoids. Journal of Chemical Ecology, 19(2), 175-183.

Angélica Casanova-Katny, M., \& Cavieres, L. A. (2012). Antarctic moss carpets facilitate growth of Deschampsia antarctica but not its survival. Polar Biology, 35(12), 1869-1878.

Bedernichek, T., Dykyy, I., Partyka, T., \& Zaimenko, N. (2020). Why WRB needs a mammalic qualifier: The case of seal colony soils. Geoderma, 371.

Bozkurt, D., Bromwich, D. H., Carrasco, J., \& Rondanelli, R. (2021). Temperature and precipitation projections for the Antarctic Peninsula over the next two decades: Contrasting global and regional climate model simulations. Climate Dynamics, 56(11), 3853-3874.

Caruso, T., Trokhymets, V., Bargagli, R., \& Convey, P. (2013). Biotic interactions as a structuring force in soil communities: Evidence from the micro-arthropods of an Antarctic moss model system. Oecologia, 172(2), 495-503.

Chown, S. L., Huiskes, A. H. L., Gremmen, N. J. M., Lee, J. E., Terauds, A., \& Crosbie, K. (2012). Continent-wide risk assessment for the establishment of nonindigenous species in Antarctica. PNAS, 109(13), 1-6.

Fowbert, J. A., \& Lewis Smith, R. I. (1994). Rapid population increases in native vascular plants in the Argentine Islands, Antarctic Peninsula. Arctic and Alpine Research, 26(3), 290-296.

Fry, S. C. (2017). Potassium, not lepidimoide, is the principal 'allelochemical' of cress-seed exudate that promotes amaranth hypocotyl elongation. Annals of Botany, 120(4), 511-520.

Grodzinsky, A. M. (Ed.). (1987). Eksperimentalnaya allelopatiya [Experimental allelopathy]. Naukova Dumka, Kyiv (in Russian).

Gutt, J., Isla, E., Xavier, J. C., Adams, B. J., Ahn, I.-Y., Cheng, C.-H. C., Colesie, C., Cummings, V. J., di Prisco, G., Griffiths, H., Hawes, I., Hogg, I., McIntyre, T., Meiners, K. M., Pearce, D. A., Peck, L., Piepenburg, D., Reisinger, R. R., Saba, G. K., Schloss, I. R., Signori, C. N., Smith, C. R., Vacchi, M., Verde, C., \& Wall, D. H. (2021). Antarctic ecosystems in transition - life between stresses and opportunities. Biological Reviews, 96(3), 798-821.
Hadacek, F., Bachmann, G., Engelmeier, D., \& Chobot, V. (2011). Hormesis and a chemical raison d'ětre for secondary plant metabolites. Dose-Response, 9, 79-116.

Haussmann, N. S., Rudolph, E. M., Kalwij, J. M., \& McIntyre, T. (2013). Fur seal populations facilitate establishment of exotic vascular plants. Biological Conservation, 162, 33-40.

Ivanov, V. B. (2011). Using the roots as test objects for the assessment of biological action of chemical substances. Russian Joumal of Plant Physiology, 58(6), 1082.

Ivanova, V., Kolarova, M., Aleksieva, K., Dornberger, K., Haertl, A., Moellmann, U., Dahse, H., \& Chipev, N. (2007). Sanionins: Anti-inflammatory and antibacterial agents with weak cytotoxicity from the antarctic moss Sanionia georgico-tncinata. Preparative Biochemistry and Biotechnology, 37(4), 343-352.

Kato-Noguchi, H., Seki, T., \& Shigemori, H. (2010). Allelopathy and allelopathic substance in the moss Rhynchostegium pallidifolium. Journal of Plant Physiology, 167(6), $468-471$.

Kovár, P., Vozár, L., \& Jančovič, J. (2013). The influence of water extracts of selected turfgrass species on germination and initial growth of Poa annua L. Acta Universitatis Agriculturae et Silviculturae Mendelianae Brunensis, 61(3), 677-681.

Minocha, R., Martinez, G., Lyons, B., \& Long, S. (2009). Development of a standardized methodology for quantifying total chlorophyll and carotenoids from foliage of hardwood and conifer tree species. Canadian Journal of Forest Research, 39(4), 849-861.

Molina-Montenegro, M. A., Bergstrom, D. M., Chwedorzewska, K. J., Convey, P., \& Chown, S. L. (2019). Increasing impacts by Antarctica's most widespread invasive plant species as result of direct competition with native vascular plants. NeoBiota, 51, 19-40.

Moroz, P. A. (1990). Allelopatiya v plodovyih sadah [Allelopathy in orchards]. Naukova Dumka, Kyiv (in Russian).

Munzuroglu, O., \& Geckil, H. (2002). Effects of metals on seed germination, root elongation, and coleoptile and hypocotyl growth in Triticum aestivum and $\mathrm{Cu}$ cumis sativus. Archives of Environmental Contamination and Toxicology, 43(2), 203-213.

Parnikoza, I., Abakumov, E., Korsun, S., Klymenko, I., Netsyk, M., Kudinova, A., \& Kozeretska, I. (2016). Soils of the Argentine Islands, Antarctica: Diversity and characteristics. Polarforschung, 86(2), 83-96.

Parnikoza, I., Convey, P., Dykyy, I., Trokhymets, V., Milinevsky, G., Tyschenko, O., Inozemtseva, D., \& Kozeretska, I. (2009). Current status of the Antarctic herb tundra formation in the Central Argentine Islands. Global Change Biology, $15(7), 1685-1693$.

Prinsloo, G., \& Du Plooy, C. P. (2018). The allelopathic effects of Amaranthus on seed germination, growth and development of vegetables. Biological Agriculture and Horticulture, 34(4), 268-279.

Robinson, S. A., Klekociuk, A. R., King, D. H., Pizarro Rojas, M., Zúñiga, G. E., \& Bergstrom, D. M. (2020). The 2019/2020 summer of Antarctic heatwaves. Global Change Biology, 26(6), 3178-3180.

Rueden, C. T., Schindelin, J., Hiner, M. C., DeZonia, B. E., Walter, A. E., Arena, E. T., \& Eliceiri, K. W. (2017). ImageJ2: ImageJ for the next generation of scientific image data. BMC Bioinformatics, 18(1).

Sangeetha, C., \& Baskar, P. (2015). Allelopathy in weed management: A critical review. African Joumal of Agricultural Research, 10(9), 1004-1015.

Turner, J., Lu, H., White, I., King, J. C., Phillips, T., Hosking, J. S., Bracegirdle, T. J., Marshall, G. J., Mulvaney, R., \& Deb, P. (2016). Absence of 21st century warming on Antarctic Peninsula consistent with natural variability. Nature, 535(7612), 411-415.

Vaughan, D. G., Marshall, G. J., Connolley, W. M., Parkinson, C., Mulvaney, R., Hodgson, D. A., King, J. C., Pudsey, C. J., \& Turner, J. (2003). Recent rapid regional climate warming on the Antarctic Peninsula. Climatic Change, 60(3), 243-274.

Wang, W. (1991). Literature review on higher plants for toxicity testing. Water, Air, and Soil Pollution, 59(3), 381-400.

Wang, X., Sun, C., Gao, S., Wang, L., \& Shuokui, H. (2001). Validation of germination rate and root elongation as indicator to assess phytotoxicity with Cucumis sativus. Chemosphere, 44(8), 1711-1721.

Ware, C., Bergstrom, D. M., Müller, E., \& Alsos, I. G. (2012). Humans introduce viable seeds to the Arctic on footwear. Biological Invasions, 14(3), 567-577.

Wellburn, A. R. (1994). The spectral determination of chlorophylls a and b, as well as total carotenoids, using various solvents with spectrophotometers of different resolution. Journal of Plant Physiology, 144(3), 307-313.

Whitehead, J., Wittemann, M., \& Cronberg, N. (2018). Allelopathy in bryophytes a review. Lindbergia, 41(1).

Zaimenko, N., Bedernichek, T., \& Khoyetskyy, P. (2016). Allelopaticheskaya aktivnost lugovika antarkticheskogo (Deschampsia antarctica E. Desv.) v kontekste globalnyih izmeneniy klimata [Allelopathic activity of Antarctic hair grass in context of global climate changes]. Bulleten Botanicheskogo Sada-Instituta DVO RAN, 15, 26-28 (in Russian). 